Ionizing Aromatic Compounds in Petroleum by Electrospray with $\mathrm{HCOONH}_{4}$ as

\title{
Ionization Promoter
}

Jincheng Lu, Yahe Zhang, Quan Shi ${ }^{*}$

State Key Laboratory of Heavy Oil Processing, China University of Petroleum, Beijing 102249 China

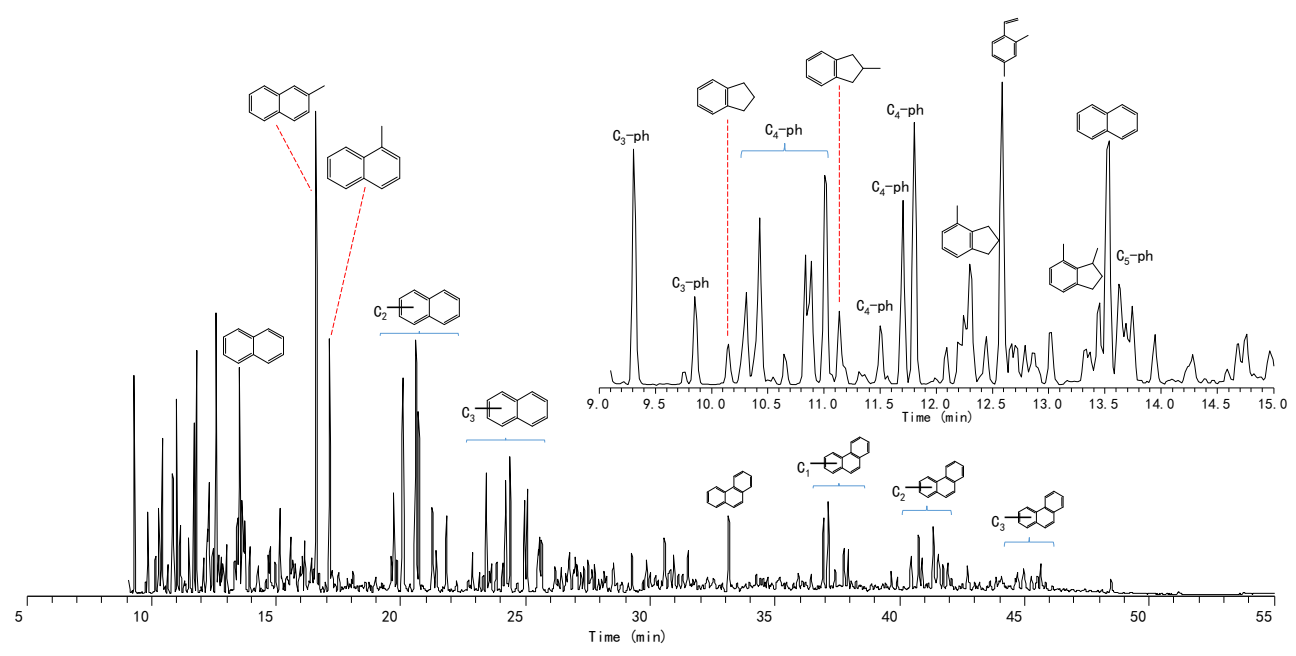

Figure S1 Total ion chromatogram of the aromatic fraction from a FCC diesel. Peaks at the left of naphthalene are mostly alkyl benzenes. 


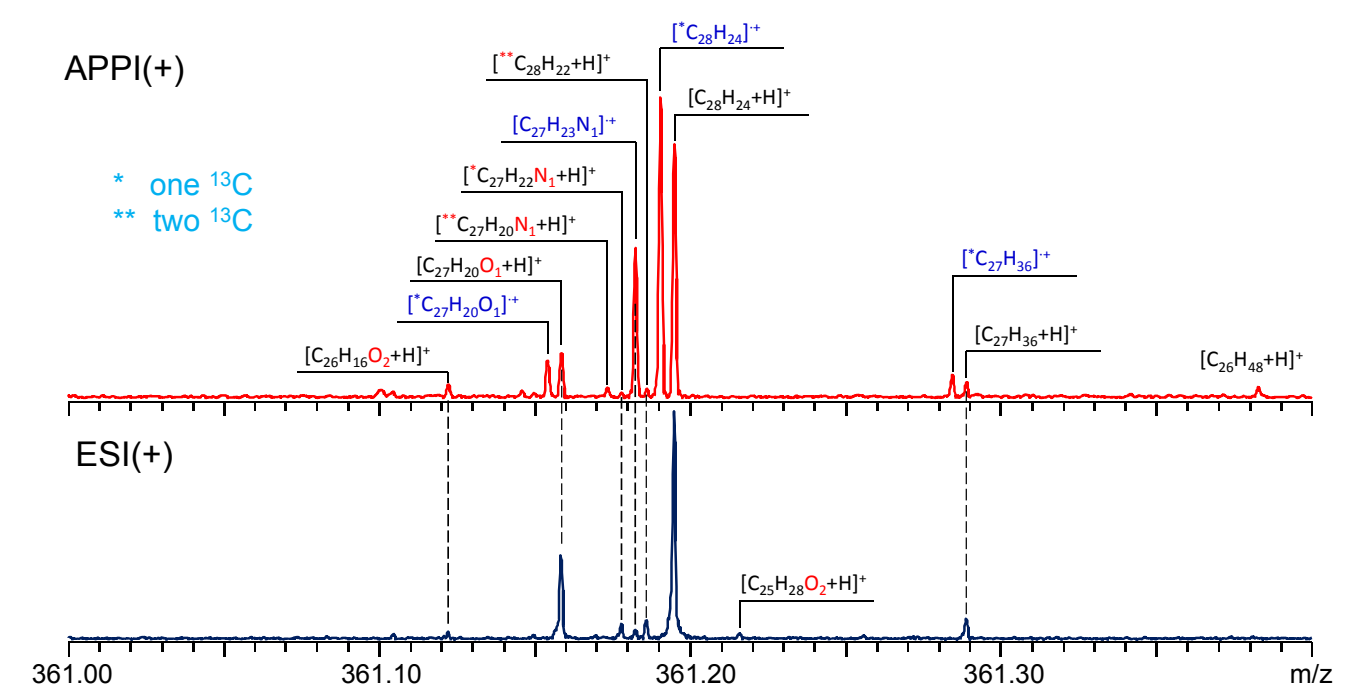

Figure S2 Expanded FT-ICR MS mass spectra of the slurry oil obtained from APPI $(+)$ and ESI(+). 